\title{
EFICIÊNCIA FOTOQUÍMICA EM FOLHAS \\ DO MAMOEIRO (Carica papaya L.) cv. GOLDEN DURANTE O ESTÁDIO REPRODUTIVO E CARACTERIZAÇÃO DA ONTOGENIA DOS FRUTOS ${ }^{1}$
}

\author{
DIOLINA MOURA SILVA² ${ }^{2}$ KETNEY TONETTO DOS SANTOS ${ }^{3}$, \\ MAÍSA MELO DUARTE ${ }^{4}$
}

RESUMO-Considerando que a fisiologia do amadurecimento dos frutos do mamoeiro envolve desde a produção de fotoassimilados, para a sua formação e desenvolvimento, até as enzimas que degradarão a parede celular, promovendo o amolecimento da polpa, o objetivo deste trabalho foi avaliar a cinética da emissão da fluorescência da clorofila $a$ em folhas do mamoeiro (Carica papaya L.) cv. Golden durante o período reprodutivo e avaliar os teores de sólidos solúveis (SS), acidez titulável (AT) e atividade da pectinametilesterase (PME) durante a ontogenia dos frutos. Os maiores índices de desempenho fotoquímico $\left(\mathrm{PI}_{\text {total }}\right)$ foram verificados nos estádios de formação e crescimento dos frutos, devido ao melhor desempenho das reações de oxirredução do fotossistema $I\left[\delta \mathrm{R}_{0} /\left(1-\delta \mathrm{R}_{0}\right)\right]$. Maior eficiência fotoquímica das plantas neste período possibilita maior demanda pelo carbono fixado para a síntese de compostos para o metabolismo celular. Em geral, os fotoassimilados são direcionados para os drenos fortes mais próximos, entretanto as sementes têm prioridade, portanto os teores de SS, AT e a atividade da PME na polpa dos frutos permaneceram constantes durante o desenvolvimento dos mesmos, sendo verificadas alterações nestas características somente no estádio de colheita. Estes resultados confirmam a participação da PME como enzima que prepara o substrato para que as demais enzimas pectinolíticas atuem, disponibilizando os ácidos orgânicos desmetilados e o início da degradação dos polissacarídeos da parece celular antes mesmo da colheita.

Termos para indexação: Fluorescência, clorofila, PME, sólidos solúveis, acidez titulável.

\section{PHOTOCHEMICAL EFFICIENCY OF PAPAYA LEAVES (Carica papaya L.) cv. GOLDEN DURING THE REPRODUCTIVE STAGE AND CHARACTERIZATION OF FRUIT ONTOGENY}

\begin{abstract}
Whereas the physiology of fruit ripening of papaya involves from the production of photoassimilates for their training and development to the enzymes that degrade the cell wall promoting pulp softening, the objective of this study was to evaluate the chlorophyll a (Chl a) fluorescence induction kinetics in of papaya (Carica papaya L.) cv. Golden leaves during the reproductive period and to evaluate the total soluble solids (SS), acidity total titratable (ATT), and activity of pectin methyl esterase (PME) during fruit ontogeny. The highest rates of photochemical performance index ( $\left.\mathrm{PI}_{\text {total }}\right)$ were observed in the stages of fruit formation and growth, due to better performance of the redox reactions of photosystem $I\left[\delta R_{0} /\left(1-\delta R_{0}\right)\right]$. Higher photochemical efficiency of plants in this period allows greater demand for fixed carbon for the synthesis of compounds for cellular metabolism. Generally, photoassimilates are directed to the closer strong drains, but the seeds have priority, so the SS, AT and PME activity in flesh fruit, remained constant during their development, and any alterations in these characteristics only in the harvest stage. These results confirm that the PME as an enzyme that prepares the substrate for the other pectic enzymes act, providing the demethylated organic acids and the beginning of the degradation of cellular wall polysaccharides even before harvest.

Index terms: Fluorescence, chlorophyll, PME, soluble solids, acidity.
\end{abstract}

\footnotetext{
1(Trabalho 066-11). Recebido em: 04-02-2011. Aceito para publicação em: 24-08-2011. Parte da dissertação de mestrado do segundo autor. ${ }^{2}$ Bióloga, Profa , Dsc., Fisiologia Vegetal, Programa de Pós-graduação em Biologia Vegetal, Universidade Federal do Espírito Santo, Av. Fernando Ferrari, 514, Goiabeiras, Vitória-ES. CEP: 29075-900. E-mail: biovegetal@terra.com.br ${ }^{3}$ Bióloga, MSc. em Biologia Vegetal, PPGBV, Universidade Federal do Espírito Santo. E-mail: ketney@bol.com.br ${ }^{4}$ Bióloga, Mestranda do PPGBV, UFES. E-mail: mamedu@hotmail.com
} 


\section{INTRODUÇÃO}

Os órgão-fonte são responsáveis pela produção de assimilados a partir da fotossíntese e são representados principalmente pelas folhas. Os fotoassimilados tanto podem ser usados na respiração como fonte energética necessária ao funcionamento da planta, como podem ser transportados e armazenados, temporariamente, em órgãos de reserva ou nos drenos, representados pelas raízes, meristemas e frutos (DUARTE; PEIL, 2010).

A atividade fotossintética influencia significativamente no desenvolvimento dos frutos e seu padrão de qualidade. Os fotoassimilados são geralmente direcionados para os drenos fortes mais próximos, e as sementes em desenvolvimento têm prioridade em relação aos drenos vegetativos. No cafeeiro, os frutos no estádio de expansão rápida alocam os fotoassimilados, e a concentração de carboidratos nas folhas decresce bruscamente, indicando ser este o período mais crítico para a concentração de carboidratos em folhas (LAVIOLA et al., 2007). Em bananeira, já foi verificado que os fotoassimilados produzidos pelas folhas são acumulados intermediariamente no pseudocaule, sendo posteriormente translocados para os frutos (SOARES et al., 2005).

A análise da fluorescência da clorofila $a$ tem possibilitado a aquisição de importantes informações sobre a relação entre estrutura e função do fotossistema II (FS II), do centro de reação (RC) e dos complexos coletores de luz (SMIT et al., 2009). O uso desta técnica tem permitido inferir a eficiência da etapa fotoquímica da fotossíntese, responsável pela produção de ATP e NADPH, que são utilizados na etapa bioquímica para a formação dos açúcares que estarão presentes nos frutos.

Diversos trabalhos demonstraram que o crescimento dos frutos depende da taxa fotossintética, que é controlada pela demanda dos frutos (LAVIOLA et al., 2007; MELO et al., 2010). No mamoeiro, são escassos ainda os resultados de pesquisas nesta área. O índice de sólidos solúveis (SS) tem sido muito utilizado em estudos de qualidade, uma vez que seu valor aumenta à medida que os açúcares vão acumulandose no fruto. A sua medição não representa o teor exato de açúcares, porque outras substâncias também se encontram dissolvidas na seiva vacuolar. No entanto, entre essas, os açúcares são as mais representativas, chegando a constituir até $90 \%$ dos sólidos solúveis (CHITARRA; CHITARRA, 2005).

Durante o desenvolvimento dos frutos, além do acúmulo de açúcares e de alterações na acidez titulável da polpa, verifica-se, também, a atividade das enzimas pectinolíticas, dentre as quais elas a pectinametilesterase (PME), enzima que está envolvida no processo de expansão celular, controle do pH na matriz da parede celular e no apoplasto, e na diferenciação celular. No período de pós-colheita, essa enzima atua na disponibilização dos ácidos orgânicos desmetilados, contribuindo para o início da degradação dos polissacararídeos acumulados na parede celular dos frutos durante sua formação (FONTES et al., 2008).

O objetivo deste trabalho foi avaliar a cinética da emissão da fluorescência da clorofila $a \mathrm{em}$ folhas do mamoeiro (Carica papaya L.) cv. Golden durante o período reprodutivo e os teores de sólidos solúveis, acidez titulável e atividade da PME durante a ontogenia dos frutos.

\section{MATERIAL E MÉTODOS}

Os dados foram obtidos a partir de plantas do mamoeiro, em uma lavoura comercial (Fazenda Herzog) localizada no município de Aracruz, norte do Espírito Santo, latitude $19^{\circ} 49^{\prime} 13$ sul, longitude $40^{\circ} 16$ '24 oeste e altitude de $50 \mathrm{~m}$ (PMA, 2010), onde a temperatura média máxima é de $30^{\circ} \mathrm{C} \pm 2$ e a mínima é de $15^{\circ} \mathrm{C} \pm 2$ (FEITOSA, 1986), com precipitação média de $1.183 \mathrm{~mm}^{-1} \mathrm{ano}^{-1}$ (CASTRO; SCARDUA, 1985). O plantio foi efetuado em fileiras duplas, com espaçamento de 3,6 m entre linhas e 2,0 m entre plantas, sendo plantadas três mudas por cova (dimensões de $50 \times 30 \times 30 \mathrm{~cm}$ ). O desbaste foi efetuado após a sexagem das plantas, aos quatro meses do transplantio, permanecendo apenas uma planta hermafrodita por cova. O solo foi caracterizado como do tipo arenoso, com matéria orgânica variando de 1,5 a 2,6 dag. $\mathrm{kg}^{-1}$ durante o período de estudo. Utilizou-se o sistema de irrigação por microaspersão.

Inicialmente, 80 plantas do mamoeiro $(\mathrm{Ca}$ rica papaya L.) cv. Golden, com quatro meses de idade, foram selecionadas aleatoriamente. Em cada planta, duas flores, ainda fechadas, foram marcadas, perfazendo um total de 160 flores. O crescimento dos frutos foi avaliado mensalmente, desde a antese até atingirem o estádio dois de maturação, época da colheita comercial, o que ocorreu aos 135 dias pósantese (DPA). As amostragens foram realizadas aos 30; 60; 90 e $135 \mathrm{DPA}$, perfazendo quatro épocas de amostragem. A cada amostragem, 20 plantas com flores marcadas eram selecionadas casualmente dentro da lavoura nas quais eram realizadas medições da fluorescência da clorofila $a$ e, em seguida, eram colhidos os frutos marcados. Cada um destes, constituindo uma unidade experimental, foi levado para o Laboratório de Ecofisiologia Vegetal da Universidade Federal do Espírito Santo (UFES), onde 
se realizaram as análises de qualidade.

Os estádios de desenvolvimento dos frutos foram considerados como descritos a seguir: formação - 30 DPA; crescimento - 60 DPA, maturação fisiológica - 90 DPA, e colheita - 135 DPA.

A emissão da fluorescência da clorofila $a$ foi realizada utilizando-se de um fluorômetro portátil (HandyPEA, Hansatech, King's Lynn, Norkfolk, UK). As medidas foram realizadas em folhas jovens completamente expandidas, adaptadas ao escuro, por um período suficiente para a oxidação completa do sistema fotossintético de transporte de elétrons. Logo após, as folhas foram submetidas a um pulso de luz saturante de $3.000 \mu \mathrm{mol} \mathrm{m} \mathrm{m}^{-2} \mathrm{~s}^{-1}$. As medidas tiveram duração de 1 segundo. Obtidas as curvas OJIP da fluorescência da clorofila $a$ onde os passos O, J, I e $\mathrm{P}$ representam, respectivamente, a intensidade de fluorescência medida a $50 \mu \mathrm{s}, 2 \mathrm{~ms}, 30 \mathrm{~ms}$ e, para o passo $\mathrm{P}$, que é a fluorescência máxima $\left(\mathrm{F}_{\mathrm{M}}\right)$, calculouse o $\mathrm{tF}_{\mathrm{M}}$ (tempo para atingir $\mathrm{F}_{\mathrm{M}}$ ), neste trabalho, medido em cerca de $300 \mathrm{~m}$. Os dados da intensidade da fluorescência foram então normalizados para fluorescência variável relativa $\left[\mathrm{V}_{\mathrm{t}}=\left(\mathrm{F}_{\mathrm{t}}-\mathrm{F}_{\mathrm{M}}\right) /\left(\mathrm{F}_{\mathrm{M}}-\mathrm{F}_{0}\right)\right]$ $\mathrm{e}$, a seguir, foram calculadas as diferenças entre os cinco estádios de desenvolvimento, tomando-se como referência o estádio de formação do fruto, obtendose $\Delta \mathrm{V}_{\mathrm{t}}=\mathrm{F}_{\text {estádio desenvol }}-\mathrm{F}_{\text {referência }}$ (CHEN et al., 2011). Os dados da fluorescência transiente OJIP foram em seguida detalhados, usando-se o Teste JIP (STRASSER; STRASSER, 1995), com o software Biolyzer (Laboratório de Bioenergética, Universidade de Genebra, Suíça) obtendo-se o índice de desempenho fotoquímico total $\left(\mathrm{PI}_{\text {total }}\right)$. Este índice foi calculado a partir da densidade do centro de reação (RC/ABS), da eficiência de captura dos fótons, $\varphi_{\mathrm{P}_{0}} /\left(1-\varphi_{\mathrm{P}_{\mathrm{o}}}\right)$, da eficiência de transporte de elétrons do FSII, $\psi \mathrm{E}_{0} /$ (1- $\psi E 0)$, e da eficiência do fluxo de transporte de elétrons até os aceptores finais do FSI, $\delta_{\mathrm{Ro}_{0}} /\left(1-\delta_{\mathrm{Ro}}\right)$ com a equação: $\mathrm{PI}_{\text {total }}=(\mathrm{RC} / \mathrm{ABS}) \cdot\left[\varphi_{\mathrm{Po}} /\left(1-\varphi_{\mathrm{Po}}\right)\right] \cdot\left[\psi \mathrm{E}_{0} /\right.$ $(1-\psi \mathrm{E} 0)] .\left[\delta_{\mathrm{Ro}} /\left(1-\delta_{\mathrm{Ro}}\right)\right]$ (STRASSER et al., 2010).

O teor de sólidos solúveis (SS) foi obtido usando o suco extraído de uma amostra de tecido da polpa, retirada da região mediana do fruto. As leituras foram efetuadas em um refratômetro de bancada (Instrutherm, RTD - 45), e os resultados, expressos em ${ }^{\circ}$ Brix. A acidez titulável (AT) da polpa dos frutos foi obtida empregando-se a metodologia descrita por Carvalho et al. (1990) e correspondente a $1 \mathrm{~g}$ de ácido cítrico por $100 \mathrm{~g}$ de matéria fresca da polpa dos frutos. A atividade da pectinametilesterase (PME - EC 3.1.1.11) foi avaliada segundo metodologia descrita por Ratner et al. (1969) e foi expressa em $\mu \mathrm{mol} \mathrm{g}^{-1}$ $\mathrm{min}^{-1}$ (correspondente à quantidade de enzima capaz de catalisar a desmetilação da pectina correspondente a um $\mu$ mol de grupos carboxílicos por minuto).

Para as análises da fluorescência da clorofila $a$, foram utilizadas dez repetições. Os dados foram processados com o software Biolyzer (Laboratório de Bioenergética, Universidade de Genebra, Suíça). O histograma representa as variações relativas de cada parâmetro analisado. A média das médias foi usada como referência e igual à unidade. Para as características de qualidade dos frutos, determinadas durante a ontogenia, foram utilizadas cinco repetições. As médias obtidas foram comparadas entre si, pelo teste de Tukey, em nível de 5\% de probabilidade.

\section{RESULTADOS E DISCUSSÃO}

A fluorescência transiente OJIP da clorofila $a$ é apresentada na Figura 1. Observa-se que todas as curvas são tipicamente polifásicas. As curvas dos estádios de formação e crescimento dos frutos mostraram alterações que podem indicar melhor eficiência fotoquímica (Figuras 1A). Tal sugestão é subsidiada pelos valores calculados da área acima de cada curva. Esta área, entre $\mathrm{F}_{0} \mathrm{e} \mathrm{F}_{\mathrm{M}}$, aumentou nestes dois estádios quando comparados às demais fases de desenvolvimento (dados não mostrados). Segundo Mehta et al. (2010), a área acima da curva OJIP é proporcional ao estado de oxidação dos aceptores de elétrons no lado redutor do FSII e inversamente proporcional ao estado de redução. Quanto maior é essa área, maior é a transferência de elétrons do centro de reação (RC) para o 'pool' de plastoquinona (PQ). Isto porque há maior eficiência na capacidade de reoxidação da Quinona $\mathrm{A}$ induzindo à eficiência no transporte de elétrons excitados do intersistema até o FSI (OUKARROUM et al., 2009).

As curvas formadas na rápida subida da fluorescência, desde $\mathrm{F}_{0}$ até $\mathrm{F}_{\mathrm{M}}$, desde trabalho, são semelhantes àquelas obtidas em diversos estudos realizados, desde Strasser et al. (1995), contendo três fases, O-J, J-I e I-P, que têm fornecido fortes evidências experimentais que refletem os três diferentes processos de redução da cadeia de transporte de elétron.

As diferenças entre cada estádio do desenvolvimento dos frutos podem ser observadas com maiores detalhes na figura $1 \mathrm{~B}$, onde se calculou a razão dos valores alcançados pelas curvas OJIP: $\Delta \mathrm{V}$ $=\mathrm{V}_{\text {estádio }}-\mathrm{V}_{\text {referência }}$. A diferença cinética revela bandas que estão normalmente escondidas entre as medidas O, J, I e P das curvas "cruas" ou com normalizações transientes (STRASSER et al., 2004). Durante a antese e crescimento dos frutos, houve melhor eficiência fotoquímica do lado aceptor do FSII, pois as 
curvas não apresentaram diferenças com a curvareferência na fase O-J, porém durante os estádios de maturação fisiológica e colheita dos frutos ocorreram aumentos na intensidade da fluorescência. Um aumento da fase O-J evidencia possível deficiência na capacidade de $\mathrm{Q}_{\mathrm{A}}{ }^{-}$em reoxidar-se. Resultados semelhantes foram descritos por Smit et al. (2009), que trabalhando com diferentes concentrações de trifluoracetato, em feijoeiro, observaram aumento da fase O-J, indicando um acúmulo de $\mathrm{Q}_{\mathrm{A}}$. Na fase J-I, houve incremento na intensidade da fluorescência durante os estádios de antese, maturação fisiológica e colheita. Este aumento refere-se a uma progressiva redução do 'pool' de PQ e foi devidamente demonstrado por Tóth et al. (2007) em folhas de cevada submetidas a altas temperaturas. Nestes mesmos estádios, observou-se também maior intensidade da fluorescência no ponto I, seguida de uma queda acentuada no ponto P. A fase mais lenta da subida de fluorescência, a fase I-P, geralmente dura de 30 a $300 \mathrm{~ms}$ e evidencia a dupla redução da plastocianina (PC) ${ }^{+}$e de $\mathrm{P}_{700}{ }^{+}$no fotossistema I (FSI). Neste trabalho, observa-se que houve diferenças na fase I-P entre os diferentes estádios do desenvolvimento dos frutos. Pode-se notar que, durante o estádio de crescimento dos frutos, a fase I-P foi a que mais se aproximou da curva de referência, demonstrando uma peculiar característica deste estádio em relação à atividade fotoquímica do FSI.

Portanto, as curvas OJIP revelaram que, durante os estádios de maturação e colheita dos frutos, as plantas do mamoeiro Golden possivelmente possuem menor capacidade de reoxidação de $\mathrm{Q}_{\mathrm{A}}{ }^{-}$no fotossistema II (FSII), gerando um acúmulo de $\mathrm{Q}_{\mathrm{A}}$ reduzida e, consequentemente, uma redução do transporte de elétrons a partir daí. Este fato refletese no FSI, onde se encontram os aceptores finais de elétrons, vindos do intersistema. Estes resultados permitem sugerir atenção no manejo da irrigação e da nutrição da cultura antes ou durante estes estádios onde a maior força do dreno (fruto) requer maior eficiência da fonte (fotossíntese) (LAVIOLA et al., 2007; SOARES et al., 2005).

Segundo Strasser et al. (2004), obtém-se melhor detalhamento da curva OJIP quando se aplica o teste JIP. Os parâmetros resultantes desse teste permitem avaliar as especificidades da cinética da fluorescência transiente, quantificando o desempenho fotoquímico desde a absorção de luz no complexo-antena até a redução dos aceptores finais de elétrons do FSI. Observam-se na Figura 2, os parâmetros que originaram o índice de desempenho total $\left(\mathrm{PI}_{\text {total }}\right)$ da etapa fotoquímica. Cada desvio do comportamento-padrão demonstra um impacto fracionário do estádio de desenvolvimento analisado.

Durante os estádios de antese e maturação fisiológica, o índice de desempenho total $\left(\mathrm{PI}_{\text {total }}\right)$ apresentou-se abaixo da média, consequência do menor desempenho das reações de oxirredução do FSI $\left[\delta \mathrm{R}_{0} /\left(1-\delta \mathrm{R}_{0}\right)\right]$. Este resultado confirma aquele observado na Figura $1 \mathrm{~A}$, onde as maiores diferenças foram encontradas no ponto I.

Durante os estádios de formação e crescimento do fruto, ocorreu um aumento de $\delta \mathrm{R}_{0} /\left(1-\delta \mathrm{R}_{0}\right)$, acompanhado também por um aumento no $\mathrm{PI}_{\text {total }}$. Van Heerden et al. (2007) observaram boa correlação entre um declínio na capacidade de assimilação $\mathrm{CO}_{2}$ e um declínio no índice de desempenho $\left(\mathrm{PI}_{\mathrm{ABS}}\right) \mathrm{em}$ dois arbustos de deserto. Eles sugeriram que essa observação é evidência para um vínculo entre mudanças nas propriedades da fluorescência transiente OJIP e a capacidade fotossintética global.

Maior eficiência de redução dos aceptores finais de elétrons do FSI indica maior eficiência na formação de ATP e NADPH, na fase fotoquímica. Esses eventos podem incrementar a taxa fotossintética, uma vez que, durante o desenvolvimento do fruto, há maior demanda por fotoassimilados. Por sua vez, estes deverão ser utilizados na formação de novas células, aumento de solutos e diminuição do potencial hídrico com consequente aumento da entrada de água nas células (alongamento celular) e do metabolismo respiratório.

Já nos estádios de maturação fisiológica e de colheita do fruto, ocorreu redução em $\delta \mathrm{R}_{0} /\left(1-\delta \mathrm{R}_{0}\right)$. Como consequência, também ocorreu queda no índice de desempenho total, mesmo tendo havido um aumento na densidade de centros de reação ativos no FSII (RC/ABS) nestes últimos dois estádios. Maior eficiência fotoquímica das plantas nestes estádios de desenvolvimento dos frutos é devido à maior demanda por carbono fixado para a síntese de compostos de armazenamento e de translocação e para o metabolismo celular. Devido a isso, mudanças nos teores de SS, na AT e na atividade da PME (Tabela 1), somente foram observadas no estádio de colheita dos frutos.

Os valores obtidos para SS foram inferiores aos normalmente encontrados para os frutos do mamoeiro cv. Golden, que é $10-12{ }^{\circ}$ Brix. Um aumento no teor de SS, neste trabalho, foi observado no estádio II de colheita dos frutos, porém ainda abaixo daquele esperando $\left(8,72^{\circ} \mathrm{Brix}\right)$. Segundo Broetto (2007), à medida que o fruto vai amadurecendo, ocorre hidrólise de carboidratos de cadeia longa e, consequentemente, aumento nos teores de açúcares simples. Neste período, também ocorre a disponibilização dos ácidos orgânicos desmetilados e o início da degradação dos polissacarídeos, acumulados na 
parede celular dos frutos, no período da colheita, confirmando a participação da PME.

A atividade da PME na polpa dos frutos apresentou-se estável durante todo o período de formação, crescimento e maturação fisiológica. Esta atividade aumentou somente na fase de colheita dos frutos. Estes dados corroboram os obtidos por Gonçalves et al. (2006) que, trabalhando com figo, observaram uma constância na atividade dessa enzima durante o desenvolvimento dos frutos. Neste período, a enzima está envolvida em vários processos, como o de expansão celular, o controle do $\mathrm{pH}$ na matriz da parede celular e no apoplasto, e a diferenciação celular.

Neste trabalho, o aumento da atividade da PME foi verificado a partir do início do amadurecimento do fruto. Fontes et al. (2008), trabalhando com mamoeiro, comprovaram que esta enzima atua disponibilizando o substrato, o ácido poligalacturônico desmetilado, para a poligalacturonase (PG), outra enzima envolvida no amaciamento de polpa.

Enquanto o índice de SS e a atividade da PME aumentaram no estádio de colheita dos frutos, a AT, representada principalmente pelo ácido cítrico, contida na polpa dos mesmos diminuiu no estádio de colheita comercial (Tabela 1). Segundo Chitarra e Chitarra (2005), a diminuição na acidez titulável acontece em decorrência da diminuição do teor de ácidos orgânicos, conforme a maturação das frutas devido ao seu uso como substrato no processo respiratório ou de sua conversão em açúcares. É importante ressaltar que o mamão é um fruto climatérico, ou seja, seu amadurecimento ocorre após a colheita devido a um aumento rápido e acentuado na atividade respiratória, o que explica a diminuição na AT mesmo ocorrendo a disponibilização dos ácidos pela PME.

Este trabalho fornece evidências que ligam as mudanças na fluorescência OJIP em condições de campo com as mudanças fisiológicas que ocorrem durante a ontogenia dos frutos do mamoeiro, uma espécie $\mathrm{C}_{3}$, sensível aos estresses abióticos (temperatura, disponibilidade hídrica, nutricional). Os resultados obtidos permitem sugerir, ainda, que a fluorescência da clorofila $a$ pode ser valiosa como uma ferramenta rápida e não invasiva para estudar as respostas do manejo da cultura durante o estádio reprodutivo do mamoeiro em diferentes condições ambientais.

TABELA 1 - Atividade da pectinametilesterase (PME), teor de sólidos solúveis (SS) e acidez titulável (AT) na polpa de frutos do mamoeiro (Carica papaya L.) cv. Golden durante a ontogenia. $(\mathrm{n}=5)$

\begin{tabular}{|c|c|c|c|}
\hline Período & PME $\left(\mu \mathrm{mol} \mathrm{g}^{-1} / \mathrm{min}^{-1}\right)$ & $\begin{array}{c}\text { SS } \\
\left({ }^{\circ} \mathrm{Brix}\right)\end{array}$ & $\begin{array}{c}\mathrm{AT} \\
\text { (Ác. cítrico g } 100 \mathrm{~g}^{-1} \text { ) }\end{array}$ \\
\hline Formação do fruto & $4,739 b^{*}$ & $6,360 \mathrm{~b}$ & $0,071 \mathrm{a}$ \\
\hline Crescimento & $4,713 \mathrm{~b}$ & $6,640 \mathrm{~b}$ & $0,069 \mathrm{a}$ \\
\hline Maturação fisiológica & $4,674 \mathrm{~b}$ & $6,460 \mathrm{~b}$ & $0,069 \mathrm{a}$ \\
\hline Colheita & $5,443 \mathrm{a}$ & $8,720 \mathrm{a}$ & $0,044 \mathrm{~b}$ \\
\hline
\end{tabular}

*Médias seguidas pela mesma letra minúscula na coluna não diferem entre si $(\mathrm{p} \leq 0,05)$, pelo teste de Tukey. 

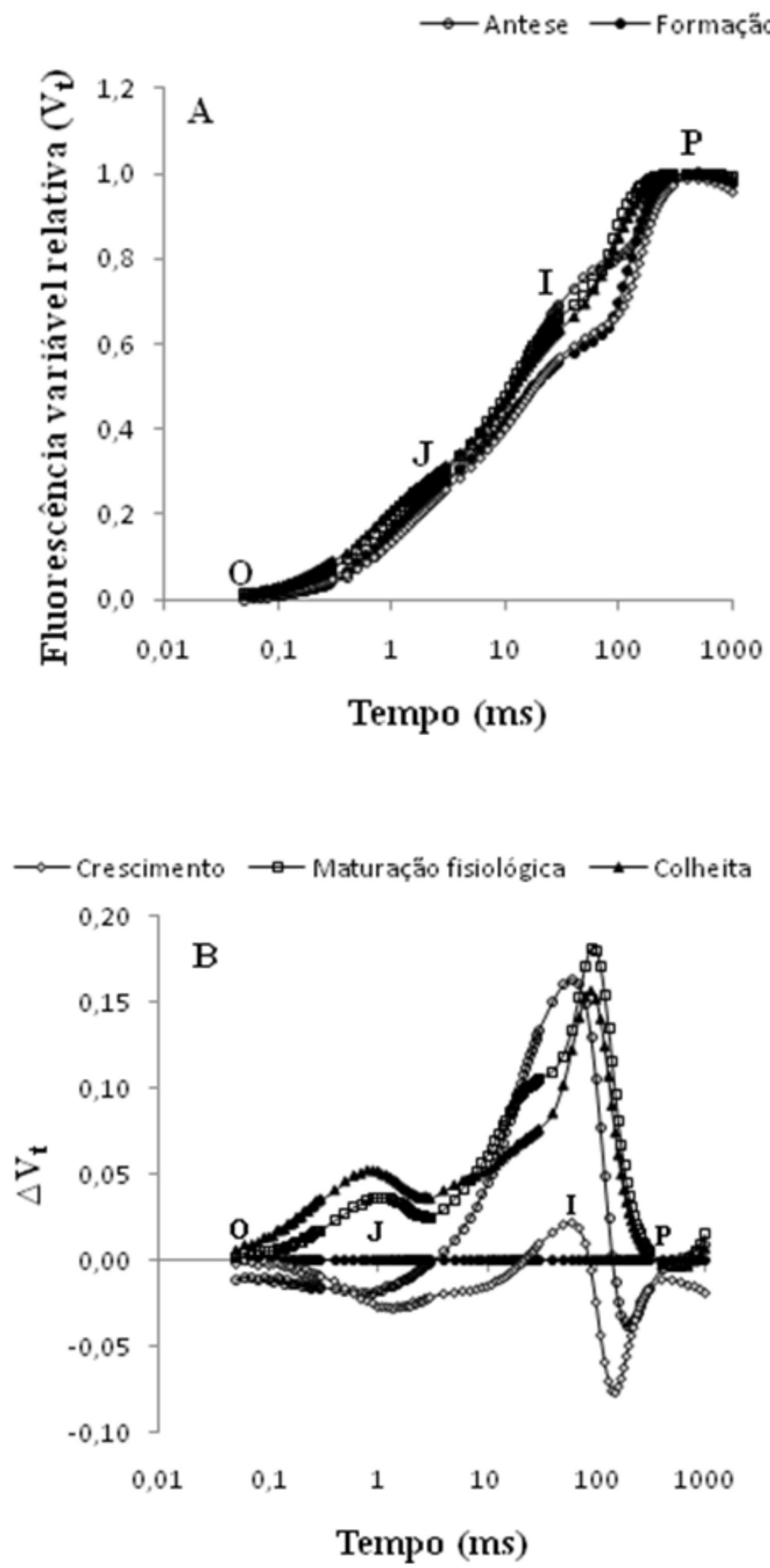

FIGURA 1 - Fluorescência da clorofila $a$ (curva OJIP) obtida em folhas de plantas do mamoeiro adaptadas ao escuro, apresentada como a cinética de diferentes expressões da fluorescência variável relativa (A) entre $\mathrm{F}_{0}$ e $\mathrm{F}_{\mathrm{M}}: \mathrm{V}_{\mathrm{t}}=\left(\mathrm{F}_{\mathrm{t}}-\mathrm{F}_{0}\right) /\left(\mathrm{F}_{\mathrm{M}}-\mathrm{F}_{0}\right) \mathrm{e}(\mathbf{B})$ a diferença entre os estádios de desenvolvimento do fruto e o estádio de formação do fruto, tomado como referência $\left(\Delta \mathrm{V}_{\mathrm{t}}=\mathrm{F}_{\text {estádio desenvol }}-\mathrm{F}_{\text {referencia }}\right)$. O eixo horizontal apresenta o tempo (ms) em escala logarítmica. As letras $\mathrm{O}$, J, I e P sinalizam o momento em que cada ponto ocorre na curva. $(n=10)$. 


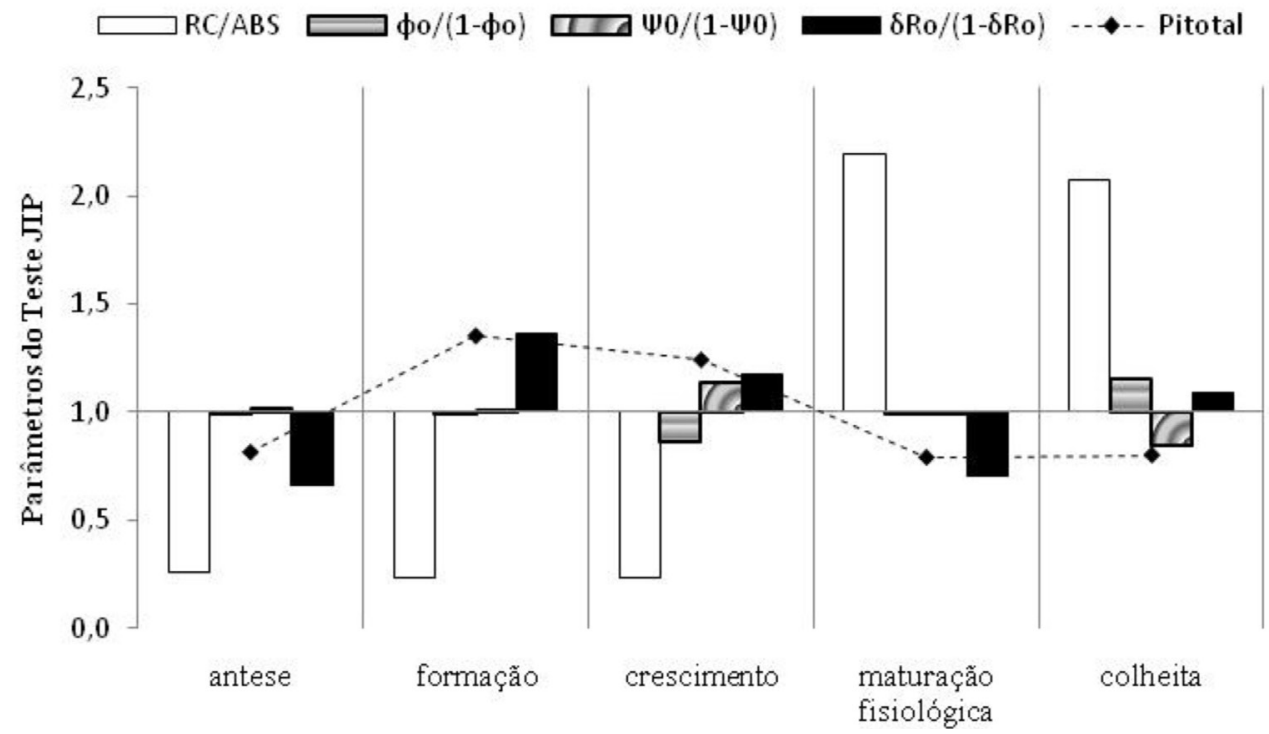

FIGURA 2 - Parâmetros da fluorescência transiente, deduzidos pelo teste JIP e expressos em valores relativos normalizados, usando como referência a média das médias como unidade, obtidos em folhas das plantas do mamoeiro (Carica papaya L.) cv. Golden, em diferentes fases de desenvolvimento dos frutos. $(\mathrm{n}=10)$.

\section{CONCLUSÕES}

As plantas do mamoeiro cv. Golden apresentam melhor atividade fotoquímica nas folhas durante épocas de grande demanda por fotoassimilados, que são os períodos de formação e crescimento dos frutos, fato comprovado por um maior $\mathrm{PI}_{\text {total }}$. Isto também se deve à maior demanda por carbono fixado para a síntese de compostos para o metabolismo celular; portanto, os teores de SS, a AT e a atividade da PME mantêm-se constantes durante todo o desenvolvimento dos frutos, tendo sua atividade aumentada a partir do estádio de colheita.

\section{AGRADECIMENTOS}

Os autores expressam seus agradecimentos às Frutas Herzog, a CAPES, ao Banco do Nordeste. Em especial ao Prof. Dr. Luiz Fernando Ganassali de Oliveira Júnior, pelas sugestões nas análises bioquímicas do trabalho.

\section{REFERÊNCIAS}

BROETTO, S. G.; SILVA, M. M.; VALBÃO, S. C.; ZAMPERLINI, G. P.; FONTES, R. V.; SILVA, D. M. Mudanças no grau de adoçamento dos frutos do mamoeiro (Carica papaya L.) 'Golden' durante o amadurecimento. In: MARTINS, D.S.; COSTA, A.N.; COSTA, A.F.S. Papaya Brasil: manejo, qualidade e mercado do mamão. Vitória: Incaper, 2007. p. 599-601.

CARVALHO, C.R.L.; MONTOVANI, D.M.B.; CARVALHO, P.R.N.; MORAES, R.M.M. Análises químicas de alimentos. Campinas: Instituto de Tecnologia de Alimentos. 1990, 121 p. (Manual Técnico)

CASTRO, L.L.F. de; SCARDUA, J. A. Estimativa da necessidade potencial de irrigação para o Estado do Espírito Santo. Cariacica: EMCAPA, 1985. p.87 (Documentos, 22).

CHEN, S.; ZHOU, F.; YIN, C.; STRASSER, R. J.; YANG, C.; QIANG, S. Application of fast chlorophyll a fluorescence kinetics to probe action target of 3-acetyl-5-isopropyltetramic acid. Environmental and Experimental Botany, Elmsford, v.71, p.269-279, 2011. 
ChITARRA, M. I. F.; CHITARRA, A. B. Pós-colheita de frutos e hortaliças: fisiologia e manuseio. 2. ed. Lavras: UFLA, 2005. 785 p.

DUARTE,T. S.; PEIL, R. M. N. Relações fonte:dreno e crescimento vegetativo do meloeiro. Horticultura Brasileira, Brasília, v. 28, p. 271-276, 2010.

FEITOSA, L.R. Carta agroclimática do Espírito Santo. Vitória: Governo do Estado, SEAG, EMCAPA, 1986. (Mapa colorido, Escala: 1:400.000).

FONTES, R. V.; SANTOS, M. P.; FALQUETO, A. R.; SILVA, D. M. Atividade da pectinametilesterase e sua relação com a perda de firmeza da polpa de mamão cv. Sunrise Solo e Tainung. Revista Brasileira de Fruticultura, Jaboticabal, v. 30, n. 1, mar. 2008.

GONÇALVES, C. A. A.; LIMA, L. C. O.; LOPES, P. S. N. Caracterização física,físico-química, enzimática e de parede celular em diferentes estádios de desenvolvimento da fruta de figueira. Ciência e Tecnologia de Alimentos, Campinas, v. 26, p. 220 $-229,2006$.

LAVIOLA, B. G.; MARTINEZ, H. E. P.; SALOMÃO, L. C. C.; CRUZ, C. D.; MENDONÇA, S. M.; NETO, A. P. Alocação de fotoassimilados em folhas e frutos de cafeeiro cultivado em duas altitudes. Pesquisa Agropecuária Brasileira, Brasília, v.42, n.11, p.1.521-1.530, 2007.

MEHTA, P.; JAJOO, A.; MATHUR, S.; BHARTI, S. Chlorophyll $a$ fluorescence study revealing effects of high salt stress on Photosystem II in wheat leaves. Plant Physiology and Biochemistry, Paris, v. 48, p. 16-20, 2010.

MELO, A.S.; SUASSUNA J. F.; FERNANDES P. D.; BRITO, M.E.B.; SUASSUNA, A.F.; AGUIAR NETTO, A.O. Crescimento vegetativo, resistência estomática, eficiência fotossintética e rendimento do fruto da melancieira em diferentes níveis de água. Acta Scientiarum Agronomy, Maringá, v. 32, n. 1, p. 73-79, 2010.

OUKARROUM, A.; SCHANSKER, G.; STRASSER, R.J. Drought stress effects on photosystem I content and photosystem II thermotolerance analyzed using Chl $a$ fluorescence kinetics in barley verieties differing in their drought tolerance. Physiologia Plantarum, Copenhagen, v. 137, p. 188-199, 2009.

PMA - Prefeitura Municipal de Aracruz. Disponível em: <http://www.pma.es.gov.br/conteudo/a-cidade/> Acesso em: jan. 2010.
RATNER, A.; GOREN, R.; MONSELISE, S. P. Activity of pectin esterase and cellulose in the abscission zone of citrus leaf explants. Plant Physiology, Minneapolis, v. 44, p. $1717-1723,1969$.

SMIT, M.F.; VAN HEERDEN, P.D.R.; PIENAAR, J.J.; WEISSFLOG, L.; STRASSER, R.J.; KRÜGER, G.H.J. Effect of trifluoroacetate, a persistent degradation product of fluorinated hydrocarbons, on Phaseolus vulgaris and Zea mays. Plant Physiology and Biochemistry, Paris, v. 47, p. 623-634, 2009.

SOARES, F. A. L.; GHEYI, H. R.; FERNANDES, P. D.; OLIVEIRA, F. H. T. O.; SILVA, F. V.; ALVES, A. N.; PEDROSA, R. M. B. Partição de fotoassimilados em cultivares de bananeira irrigadas com águas de diferentes salinidades. Revista Brasileira de Engenharia Agrícola e Ambiental, Campina Grande, v.9, p.101-107, 2005. Suplemento.

STRASSER, B. J.; STRASSER, R. J. Measuring fast fluorescence transients to address environmental questions: The JIP-test. In: MATHIS, P. (Ed.). Photosynthesis: from light to biosphere. Dordrecht: Kluwer Academic, 1995. p.977-980.

STRASSER, R. J.; TSIMILLI-MICHAEL, M.; QIANG, S.; GOLTSEV, V. Simultaneous in vivo recording of prompt and delayed fluorescence and 820 -nm reflection changes during drying and after rehydration of the resurrection plant Haberlea rhodopensis. Biochimica et Biophysica Acta, Amsterdam, v.1797, p.1.313-1.326, 2010.

STRASSER, R. J.; TSIMILI-MICHAEL, M.; SRIVASTAVA, A. Analysis of the chlorophyll a fluorescence transient. In: PAPAGEORGIOU, G.C.; GOVINDJEE (Ed.). Chlorophyll a fluorescence: a signature of photosynthesis. Dordrecht: Springer, 2004. p. 321-362.

TÒTH, S.Z.; SCHANSKER, G.; STRASSER, R.J. A non-invasive assay of the plastoquinone pool redox state based on the OJIP-transient. Photosynthesis Research, Dordrecht, v. 93, p. 193-203, 2007.

VAN HEERDEN, P. D. R.; SWANEPOEL, J. W.; KRÜGER, G. H. J. Modulation of photosynthesis by drought in two desert scrub species exhibiting $\mathrm{C}_{3}$ mode $\mathrm{CO}_{2}$ assimilation. Environmental and Experimental Botany, Elmsford, v.61, p. 124-136, 2007. 